\title{
Relação entre o número de células somáticas e o agente etiológico em vacas com mastite subclínica
}

Gabriela Bonela Dantas Leite ${ }^{[a]}$, Daniela Junqueira de Queiroz ${ }^{[a, b]^{*}}$, Mayara Gonçalves Fonseca ${ }^{[b]}$ Tainá Caroline Beletti Valente Silva ${ }^{[a]}$ Isabela Pavoni ${ }^{[a]}$, Andreza Freitas Galatti[a], Thiago Correa Neves de Souza ${ }^{[a]}$, Maria da Graça Portantiolo Corrêa ${ }^{[c]}$, Fernanda Pavinatto Toro[c], Inivaldo Corrêa ${ }^{[c]}$

\footnotetext{
[a] Centro Universitário Barão de Mauá (CBM), Ribeirão Preto, SP, Brasil

${ }^{[b]}$ Faculdade de Ciências Agrárias e Veterinárias, Universidade Estadual Paulista (UNESP), Jaboticabal, SP, Brasil

${ }^{[c]}$ Laboratório Vitafort Indústria e Comércio de Produtos Veterinários Ltda, Ribeirão Preto, SP, Brasil
}

*Autor correspondente

e-mail: danielajqueiroz@hotmail.com

\section{Resumo}

A mastite é um dos principais problemas sanitários da pecuária leiteira e seu diagnóstico baseia-se em testes que verificam quantidade de leucócitos no leite como a contagem de células somáticas (CCS). Assim, objetivou-se relacionar CCS com agente etiológico em vacas com mastite subclínica. Para tanto, coletou-se leite dos quatro quartos mamários de 80 vacas em lactação de uma mesma propriedade, que apresentavam mastite subclínica diagnosticada pelo California Mastitis Test. As amostras de leite, compostas por secreção dos quatro quartos mamários, foram coletadas em copo coletor acoplado ao sistema de ordenha e armazenadas em frascos contendo bromopol para realização de CCS (células/ mL) e coletadas diretamente do úbere do animal em frascos esterilizados para realização de exame microbiológico. A CCS foi realizada na Clínica do Leite - Esalq/ USP - Piracicaba/SP em aparelho de citometria de fluxo, e as análises microbiológicas, no Laboratório Vitafort Indústria e Comércio de Produtos Veterinários Ltda - Ribeirão Preto/ SP. Após a análise microbiológica, selecionou-se as 37 amostras nas quais se isolou apenas um microrganismo e realizou-se estatística descritiva para relacionar a CCS com o agente etiológico envolvido. Em 12 amostras, isolou-se Staphylococcus coagulase negativa e a mediana de CCS foi $448 \times 10^{3}$. Em seis amostras, isolou-se Streptococcus e a mediana de CCS foi 461,5 x 10³. Em cinco amostras, isolou-se levedura e a mediana de CCS foi $181 \times 10^{3}$. Citrobacter foi isolado em três amostras com mediana $812 \times 10^{3}$ de CCS. Enterobacter também foi isolado em três amostras com mediana $699 \times 10^{3}$ de CCS, e Escherichia coli em outras três, com mediana de $465 \times 10^{3}$ de CCS. Em duas amostras isolou-se Staphylococcus coagulase positiva e a mediana de CCS foi $796 \times 10^{3}$. E uma amostra isolou-se bactéria gram positiva com gênero não identificado e a mediana de CCS foi $409 \times 10^{3}$. Em uma outra, isolou-se Proteus e a mediana de CCS foi $1991 \times 10^{3}$, e Pseudomonas também foi 
isolada em uma amostra com mediana $622 \times 10^{3}$ de CCS. De acordo com a literatura, vacas com CCS acima de 250.000 células/mL apresentam mastite subclínica, estando de acordo com o observado no presente estudo, no qual observou-se valores de acima de 250.00 células/ mL para as todas as amostras, com exceção das amostras nas quais se isolou leveduras que apresentaram CCS abaixo de 250.000 células/mL. 